\title{
EFFECTS OF SUGGESTION AND CONDITIONING ON THE ACTION OF CHEMICAL AGENTS IN HUMAN SUB- JECTS-THE PHARMACOLOGY OF PLACEBOS 1,2
}

\author{
By STEWART WOLF \\ (From The New York Hospital and Department of Medicine, Cornell University \\ Medical College)
}

(Received for publication April 18, 1949)

The effect of administration of a drug or other chemical agent on a bit of muscle suspended in a standard solution is predictable and reproducible because it depends only on the pharmacologic action of the agent administered. The effect of administration of the same agent on an intact organism, however, is not necessarily predictable or reproducible because the pharmacologic action of the agent may either reinforce or run counter to other forces acting on the end organ at the same time. This is not a startling statement but a truism of which physicians and laymen have long been aware. Despite this awareness, drugs are often dealt with as if the intact organism were comparable to the water bath and little interest has been manifest in factors other than their pharmacologic action which may determine or modify the effects of chemical agents in the human body. The purpose of this communication is to describe some measurable "drug effects" which are not attributable to the chemical properties of the agents administered.

It is not intended here to elaborate the psychodynamic mechanisms which may be involved in such phenomena. Neither is it possible to identify with certainty or to distinguish between the various factors which modify in a given instance the action of a chemical agent. Therefore this communication is not concerned with enumerating or weighing these various factors but with illustrating the magnitude of their effects, so that in the future drugs will be assessed not only with reference to their pharmacologic action but also to the other forces at play and to the circumstances surrounding their administration.

\footnotetext{
1 Aided by grants from the Commonwealth Fund and the Estate of Lester N. Hofheimer.

2 Presented before the Annual Meeting of the American Society for Clinical Investigation, 1948.
}

\section{METHOD}

Initial observations were made on Tom, a human subject with a large gastric fistula, in whom it was possible to observe directly the gastric mucous membrane, correlating changes in color and turgidity with simultaneous measurements of secretion and motor activity (1). Four other human subjects provided supplementary experimental opportunities.

The methods used in measuring and recording the indicators of gastric function are described in detail elsewhere (1). Acid secretion is designated not only in titratable units, but also as the quantity of $0.17 \mathrm{~N} \mathrm{HCl}$ secreted by the stomach per 15 minute collection period. The figure for this quantity is derived from the volume of secretion and the total acidity with reference to a formula developed by Hollander (1). Under average circumstances the resting stomach secretion approximates $5 \mathrm{cc}$. $0.17 \mathrm{~N} \mathrm{HCl}$ per hour.

\section{OBSERVATIONS}

Among the factors which appeared to be of leading importance in the experiments which follow are: 1) The state of the end organ at the time of administration, i.e., the effect of forces already acting prior to administration of the agent; 2) the setting in which the agent was administered, including the route of administration, the presence of the experimentor and the effects of suggestion, implicit or expressed; 3) conditioning circumstances and previously established habits of reaction.

Below are detailed examples of these phenomena observed following the administration of various agents.

\section{Urogastrone}

The literature reflects considerable divergence of opinion concerning the action of urogastrone and enterogastrone on the stomach. Inhibition of acid secretion has been reported but this effect has not been consistently observed (2-5). In the published data, cognizance has not been 
TABLE I

The results of administration of capsules containing urogastrone directly into the stomach of Tom

\begin{tabular}{|c|c|c|c|c|c|c|c|c|}
\hline & 1 & 2 & 3 & 4 & 5 & 6 & 7 & 8 \\
\hline $\begin{array}{l}\text { Dose } \\
\text { Maximum effect } \\
\text { Color } \\
\text { Turgidity } \\
\text { Free acid }\end{array}$ & $\begin{array}{l}1 \text { caps. } \\
45 \mathrm{~min} . \\
55 \rightarrow 45 \\
3 \rightarrow 2 \\
50 \rightarrow 12\end{array}$ & $\begin{array}{l}1 \text { caps. } \\
60 \text { min. } \\
50 \rightarrow 40 \\
2 \rightarrow 1 \\
26 \rightarrow 0\end{array}$ & $\begin{array}{l}1 \text { caps. } \\
75 \text { min. } \\
55 \rightarrow 55 \\
3 \rightarrow 3 \\
60 \rightarrow 55\end{array}$ & $\begin{array}{l}2 \text { caps. } \\
\underset{65 \rightarrow 70}{\longrightarrow \rightarrow 4} \\
70 \rightarrow 85\end{array}$ & $\begin{array}{l}2 \text { caps. } \\
120 \text { min. } \\
60 \rightarrow 50 \\
3 \rightarrow 1 \frac{1}{2} \\
12 \rightarrow 0\end{array}$ & $\begin{array}{l}2 \text { caps. } \\
\qquad \underset{65 \rightarrow 65}{\longrightarrow} \\
3 \frac{1}{2} \rightarrow 3 \frac{1}{2} \\
58 \rightarrow 56\end{array}$ & $\begin{array}{l}2 \text { caps. } \\
75 \text { min. } \\
55 \rightarrow 40 \\
3 \rightarrow 2 \\
36 \rightarrow 12\end{array}$ & $\begin{array}{l}2 \text { caps. } \\
\underset{60 \rightarrow 60}{\longrightarrow} 60 \\
45 \rightarrow 50\end{array}$ \\
\hline
\end{tabular}

taken of the relative state of activity of the stomach at the time of administration.

Dry powder containing an as yet unmeasured quantity of urogastrone was prepared from aqueous extract of pregnant mare's urine after the removal of the fat soluble fraction. ${ }^{3}$ Page and Heffner (6) have reported the use of this same material in the treatment of peptic ulcer.

Eight experiments were performed with varying amounts of this preparation administered by

${ }^{3}$ Courtesy Parke, Davis \& Company.

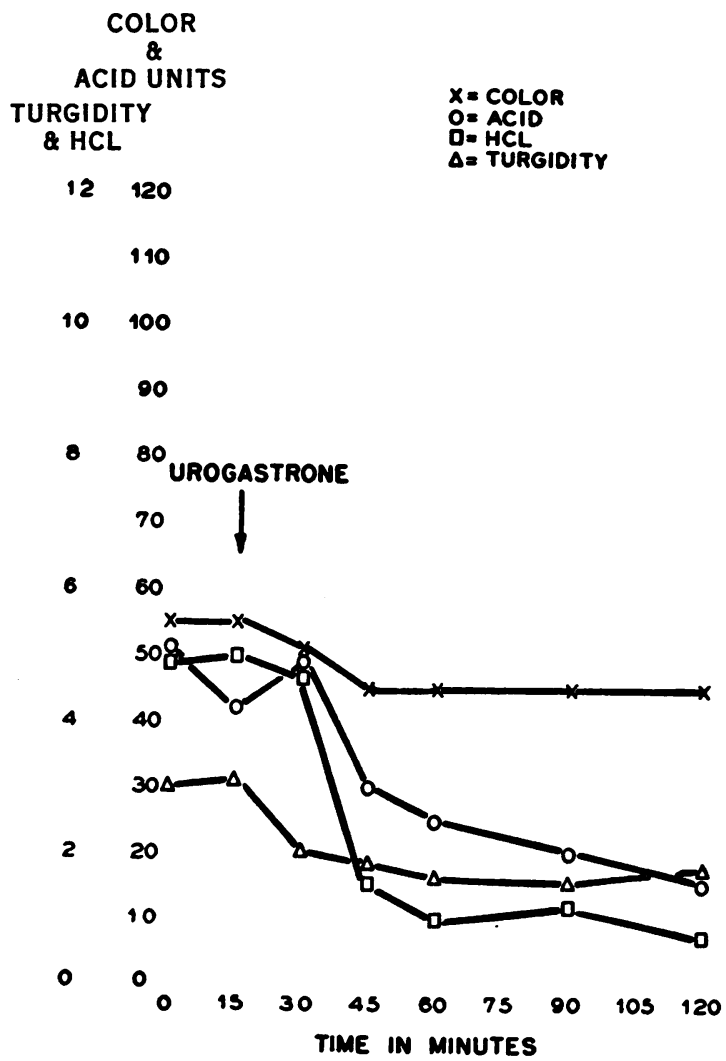

mouth. The results are shown in Table I. It will be noted that they are variable but correspond in general to the state of the gastric mucosa at the time of administration. That is, when the stomach was not hyperaemic and hypersecretive the agent induced an evident inhibition of secretion associated with pallor and diminution of turgidity. When, on the other hand, the agent was administered in the presence of gastric hyperfunction, little or no effect was noted. Two of the experiments are illustrated graphically in Fig-

\section{DISPOSSESS NOTICE LAST NIGHT}
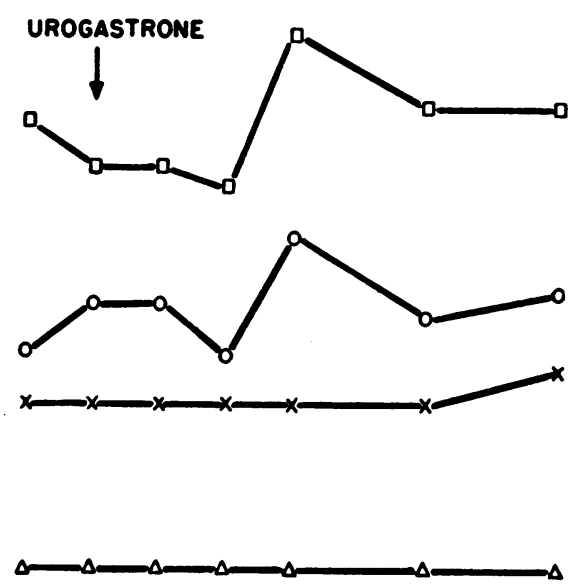

Fig. 1. The Effects of Urogastrone on the Stomach of Tom on Two Separate Occasions

On the first occasion, the stomach was in a state of relative inactivity and there resulted an evident depression of gastric function. On the second occasion, the agent administered during a phase of relative gastric hyperfunction showed no apparent effect. 
ure 1. The first was performed at a time of relative relaxation and security when gastric function was average. The second was performed in a setting of intense feelings of frustration and resentment related to Tom's receipt of a dispossess notice from his landlord on the previous day. The stomach at the time of the experiment was turgid, hyperaemic and hypersecretive. This gastric hyperfunction was actually somewhat enhanced following ingestion of the drug.

Comment. The receipt of a dispossess notice was for Tom perhaps more of a traumatic experience than it would have been for the average person at a time of housing shortage because, as pointed out in detail elsewhere (1) performance as a competent family head was with him a prime value. The experience signified to him that he was losing his hold on the family destinies, and it provoked a reaction of insecurity, anxiety and resentment. As shown in Figure 1 gastric function on this occasion actually increased following urogastrone. As reported elsewhere (1) it has repeatedly been shown that gastric hyperfunction occurs in Tom in a setting of anxiety and resentment. It seems probable that the forces re- lated to this reaction were more powerful than the pharmacologic action of urogastrone.

\section{Benadryl}

The effect on gastric acid secretion of the antihistaminic drug Benadryl has been similarly difficult to define $(7,8)$. Figure 2 illustrates the depressing effect upon gastric blood flow and acidity exerted by $50 \mathrm{mg}$. of Benadryl when the stomach was in an average state and Tom was relatively relaxed and contented. Figure 3 illustrates the relative lack of effect observed upon another morning when Tom was tense and angry because of having had to run a fruitless errand for someone whom he particularly disliked. At the time of administration of the Benadryl his gastric mucosa was intensely turgid and hyperaemic and acid values were high. Following ingestion of the same quantity of Benadryl as before there was no significant change in the measurable indicators of gastric function.

Similarly, pyribenzamine and posterior pituitary extract inhibited gastric function when the stomach was relatively inactive at the time of administration, but exerted no measurable effect when

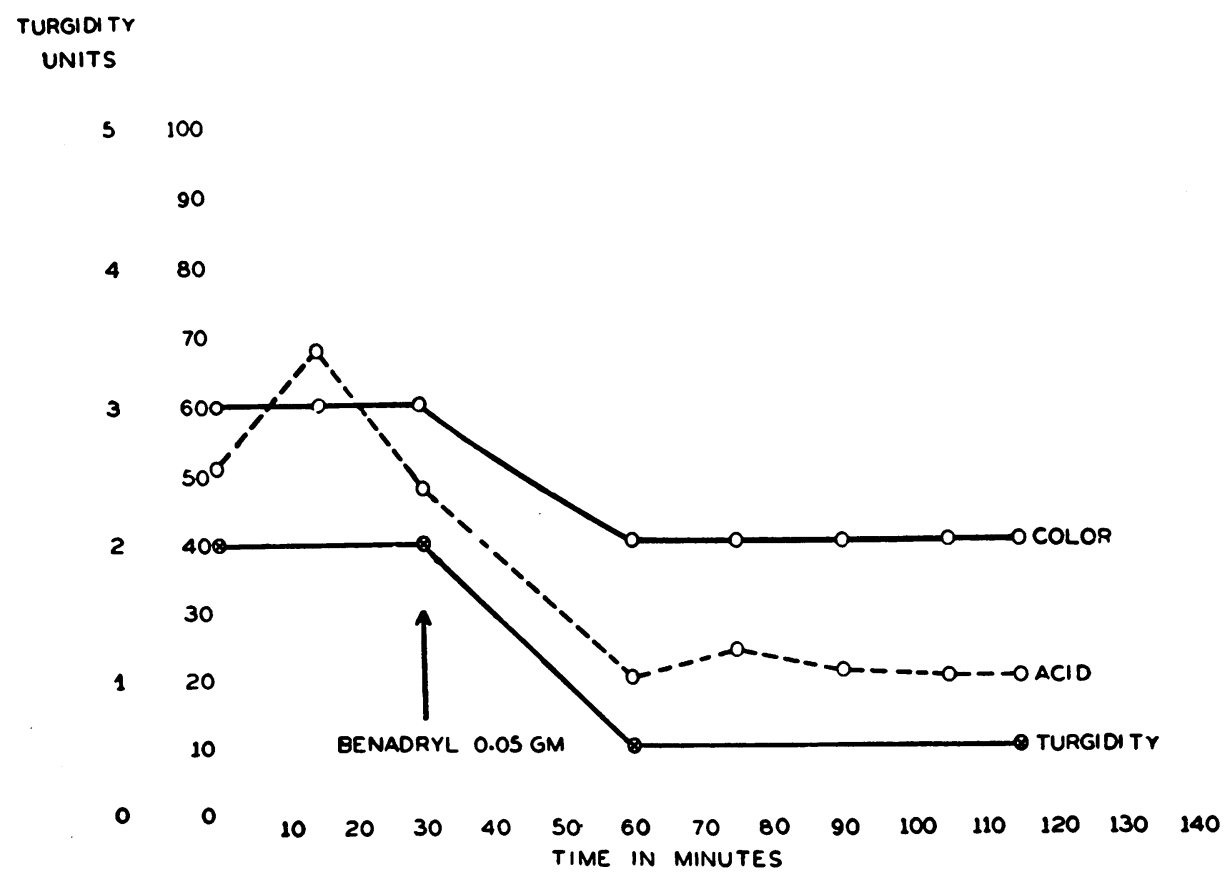

Fig. 2. Depressing Effect of Benadryl. When Administered at a Time of Average Gastric Function 


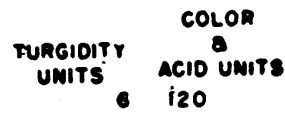

110

5100

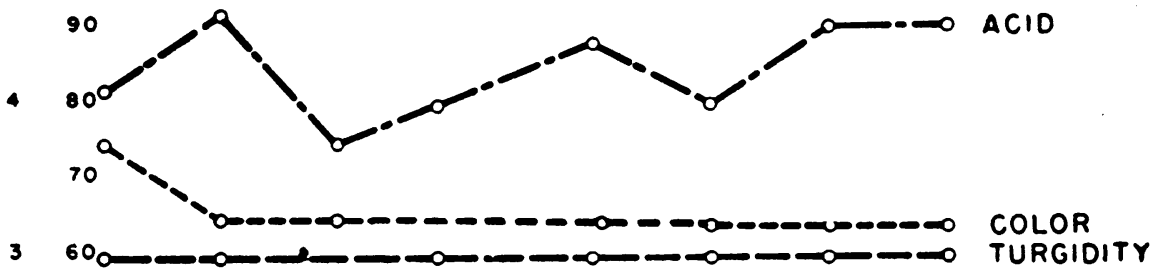

so

240

30

120

$10 \quad$ BENADRYL $0.05 \mathrm{GM}$

00

$\begin{array}{lllllllllllllll}10 & 20 & 30 & 40 & 50 & 60 & 70 & 80 & 90 & 100 & 110 & 120 & 130 & 140 & 150\end{array}$

TIME IN MINUTES

Fig. 3. Lack of Inhibiting Effect of Bena dryl Administered to a Hyperactive Stomach

the stomach was in an episode of relative gastric hyperfunction.

Comment. The discrepancies in results in these experiments which correspond roughly to the state of the gastric mucosa at the time of administration may be attributed to modification of the effectiveness of an agent by other more powerful forces acting on the end organ at the same time.

\section{Hypodermic of sterile water}

Tom always resented being stuck by a needle. Accordingly, when he was given a hypodermic injection of sterile water the effect as shown in Figure 4 was to enhance gastric blood flow and secretion.

The same category of effect was observed in experiments on the nose when procaine hydrochloride was injected into the left stellate ganglion of a human subject. As reported elsewhere in detail, this interruption of sympathetic nerve fibers to the nose regularly results in hyperaemia and

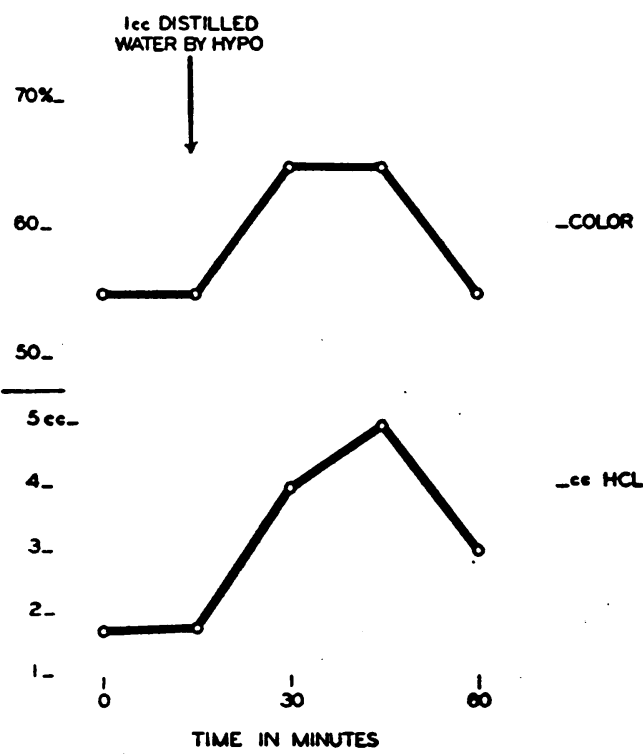

Fig. 4. InCreased Gastric Function Following Hypodermic Injection of Distilled Water

Acid secretion in this figure is expressed as cc. of 0.17 $\mathrm{N} \mathrm{HCl}$ per 15 min., as in Figures 1-3, 7-9. The recorded difference of $3 \mathrm{cc}$. is significant. 


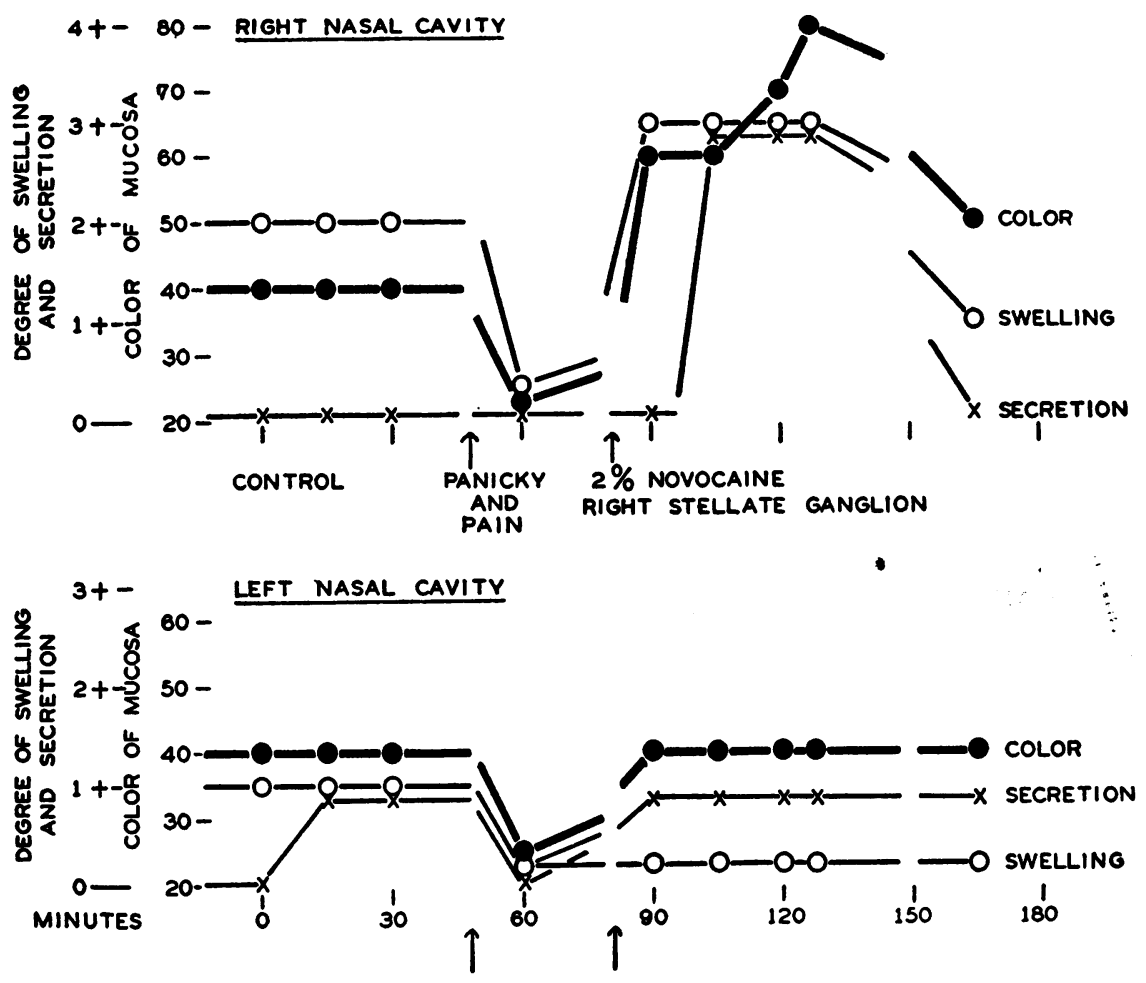

Fig. 5. Unilateral Nasal Hyperfunction Following Temporary Block of the Stellate Ganglion on that Side

Note brief period of pallor and dryness in both nostrils during fright prior to injection.

engorgement of the turbinates with increased mucus secretion (9). The injection procedure had its own effect, however, because it frightened the subject. The transitory fear reaction was accompanied by pallor and shrinkage of the turbinates and hyposecretion of mucus which preceded the sympathetic blocking effect of the procaine block as shown in Figure 5.

Comment. These effects which arise because the circumstances surrounding the administration of the agent constitute in themselves a stimulus may, of course, either reinforce or oppose the pharmacologic action of the agent administered.

\section{Ipecac}

The nausea which follows the ingestion of ipecac or indeed that induced by any nauseating stimulus is associated with interruption of contractile activity of the stomach and general relaxation and flaccidity of the organ as described in an earlier communication (10). In Figure 6A is shown the pattern observed in kymographic tracings during nausea after the ingestion of ipecac. An opposite effect attributable to a "placebo" action was experimentally induced in a 28 year old female suffering from nausea and vomiting of pregnancy who had been continuously nauseated and vomiting for two days. She was intubated with a balloon attached to a recording manometer. In Figure $6 \mathrm{~B}$ is shown the characteristic pattern of gastric inactivity which accompanies nausea (10). After a suitable control period the subject was given $10 \mathrm{cc}$. syrup of ipecac and told that it was medicine which would abolish her nausea. Within 20 minutes the nausea had subsided completely and did not recur until the following morning. As shown in Figure $6 \mathrm{~B}$ the stomach began to display normal contractile activity coincident with the disappearance of nausea.

A second subject, also a 28 year old female, had had recurrent nausea for several months associated with a reactive depression. A kymographic recording from her stomach revealed the characteristic absence of contractile activity during nausea. After a suitable control period she was 

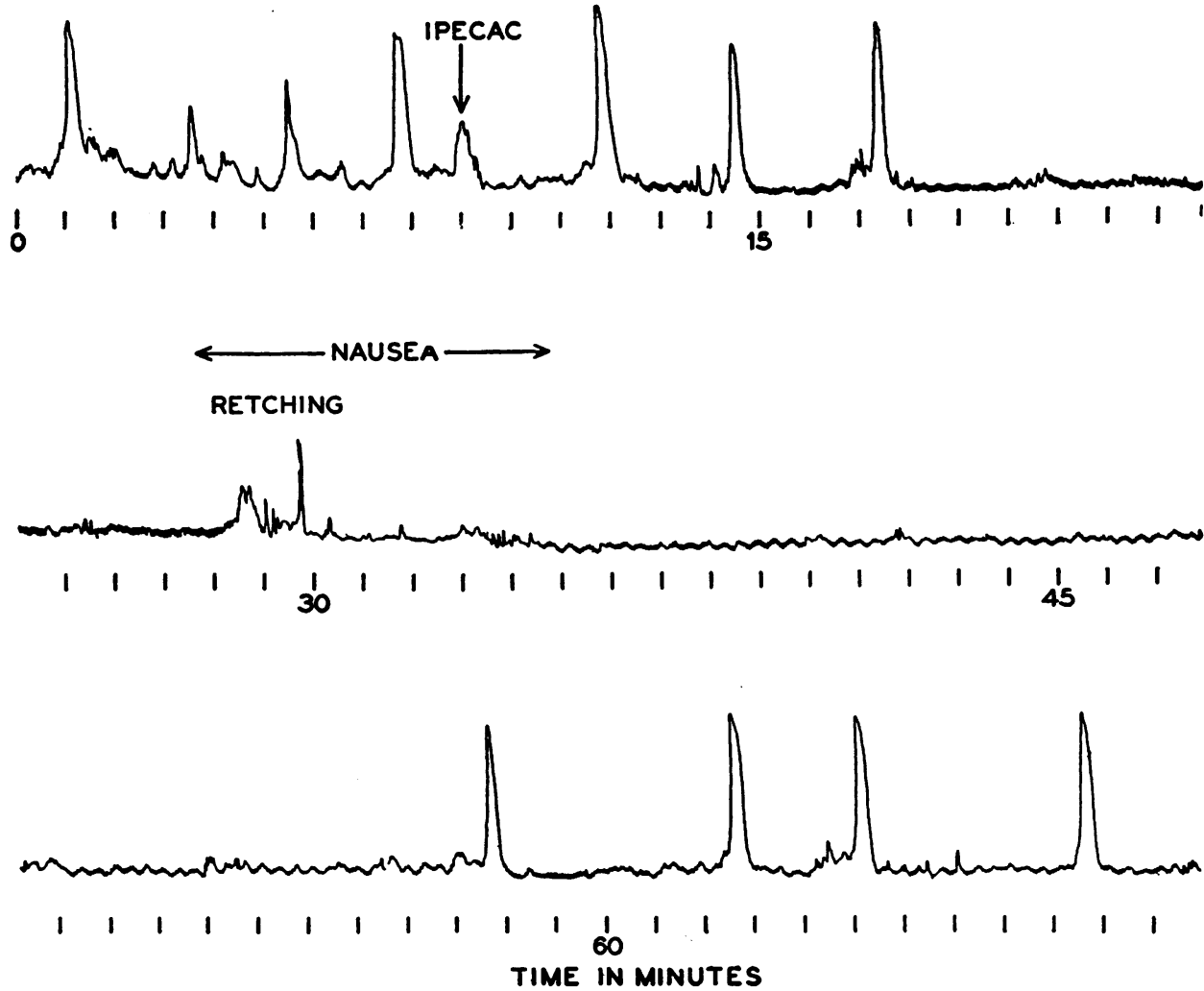

Fig. 6a. Usual Effect of Ingestion of $10 \mathrm{cc}$. Syrup of Ipecac

Note interruption of contractile activity of the stomach during nausea.

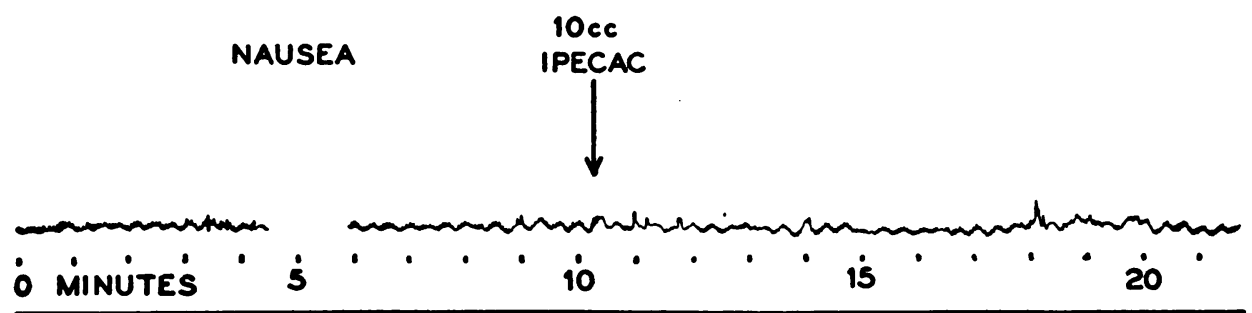

NAUSEA GONE

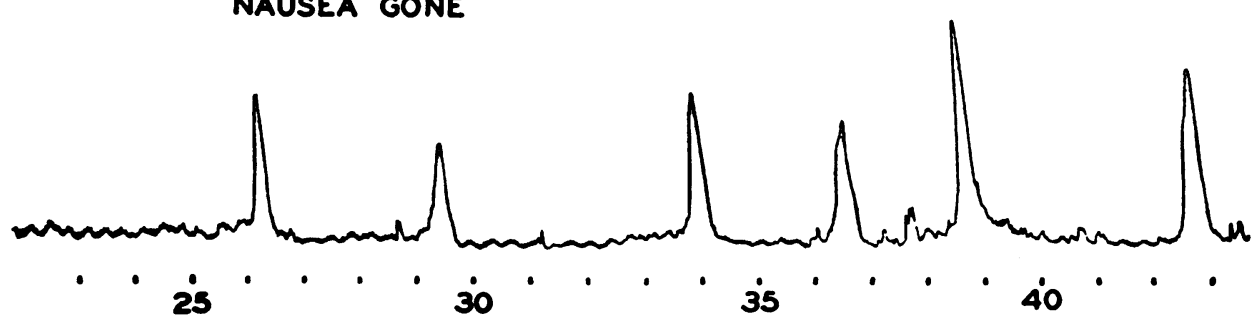

Fig. 6b. Reversal of Ipecac Effect by Suggestion

Note disappearance of nausea with resumption of gastric contractions at a time when ipecac is usually inducing nausea and interrupting contractions. 


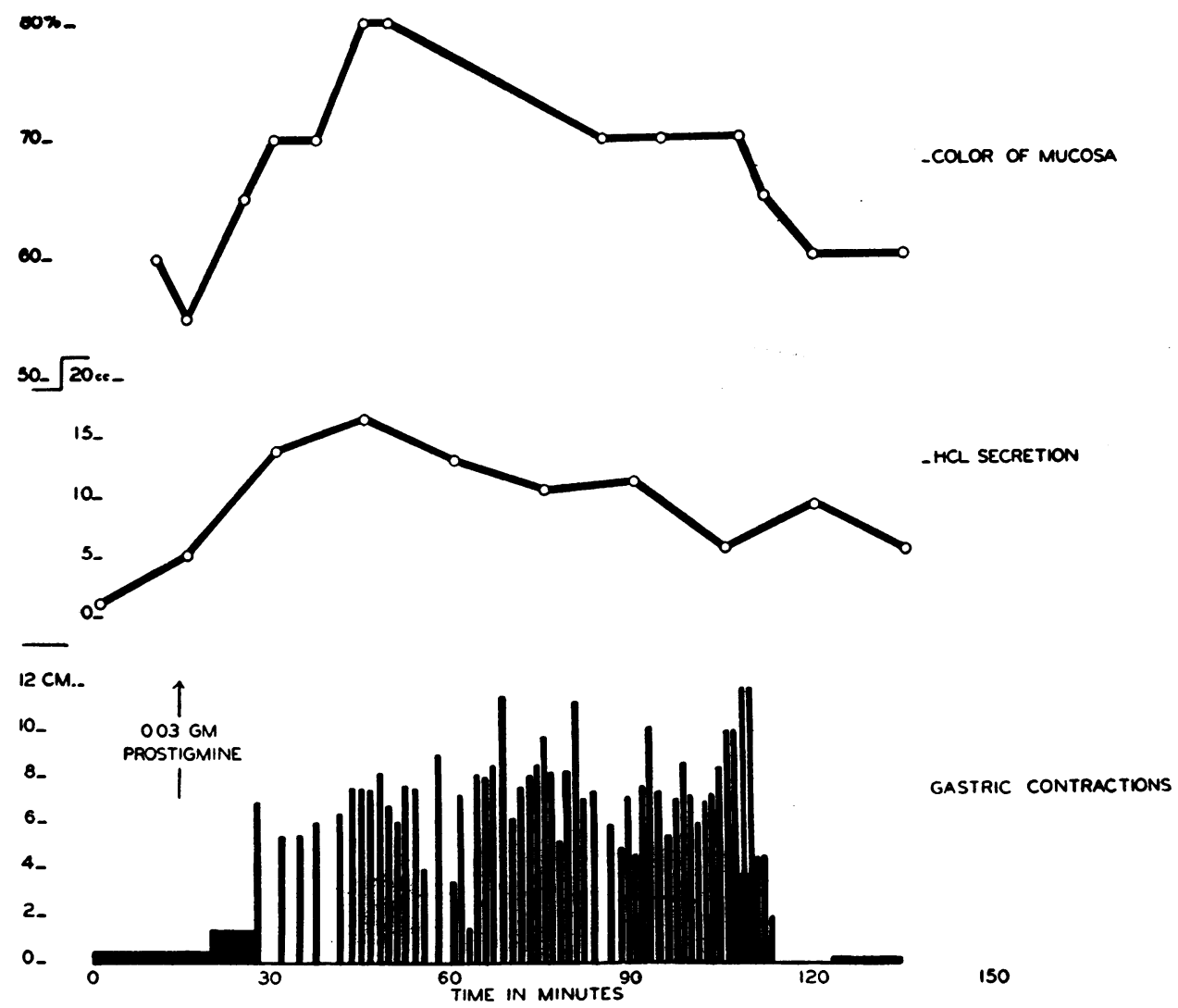

Fig. 7. Usual Effect of Prostigmine 0.03 Gm. Administered by Mouth

given $10 \mathrm{cc}$. syrup of ipecac directly into the stomach through a Levine tube. Repeatedly on previous occasions this amount of ipecac when swallowed had induced nausea and vomiting. On this occasion, however, not tasting and not knowing what she had been given, she was told that the agent would abolish her nausea; within $30 \mathrm{~min}$ utes nausea was gone and small waves of contraction were recorded from the stomach. Sixty minutes later when nausea had recurred with associated gastric hypomotility a second dose of ipecac was introduced into the Levine tube, this time with the reassurance that the nausea would be effectively abolished. Nausea disappeared again in $\mathbf{1 5}$ minutes and gastric contractions were resumed. No further nausea was experienced that day.

Comment. The above "placebo" actions depended for their force on the conviction of the patient that this or that effect would result. It is

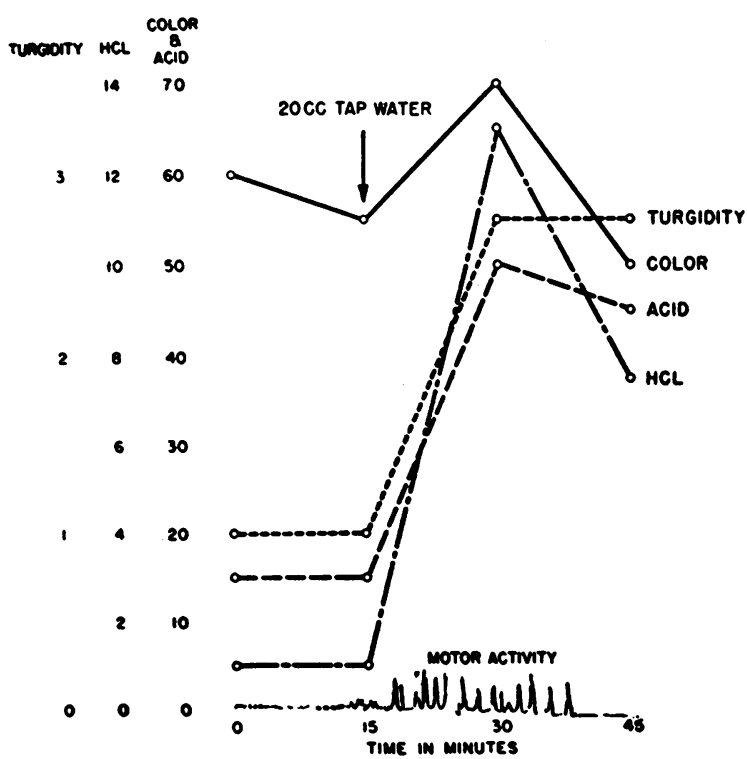

Fig. 8. Apparent Stimulating Effect of Tap Water Following Suitable Conditions of the Stomach 


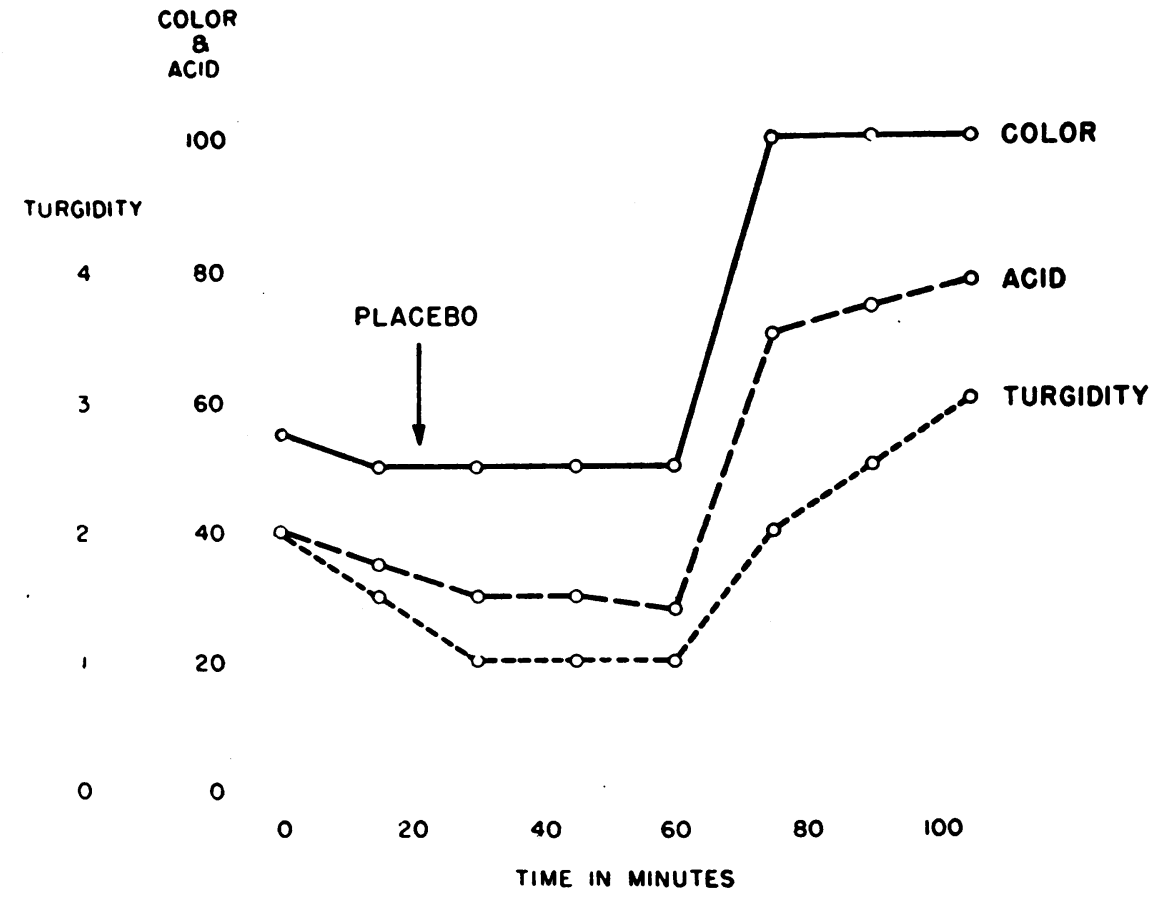

Fig. 9. Marked Increase in Gastric Function Following Ingestion of Lactose Placebo

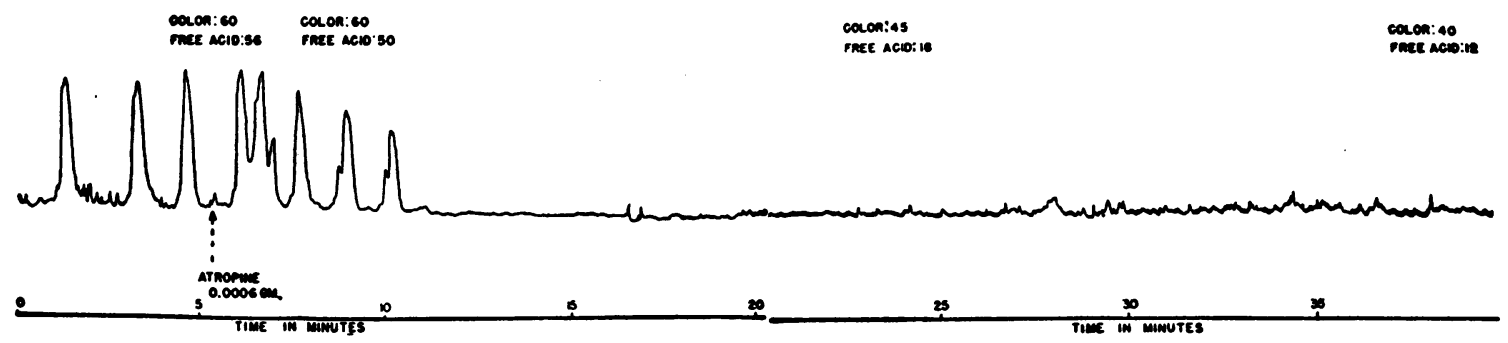

Fig. 10A. Usual Inhibiting Effect on Gastric Motor Activity of 0006 Gm. Atropine Hypodermically

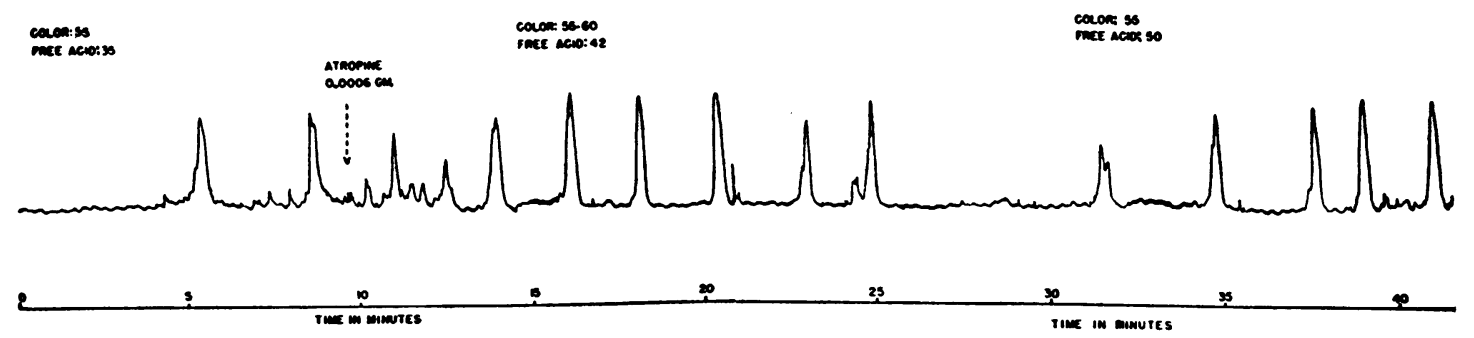

Fig. 10b. Reversal of Atropine Effect on the Stomach After Suitable Conditioning with Increased Contractile Activity Following Injection of .0006 Gm. 
likely that this mechanism is operative in part in any enthusiastically pursued therapeutic regime as well as in the successful cures of faith healers. It has even been shown experimentally that the threshold for pain perception may be greatly raised by suggestion (11).

\section{Prostigmine, tap water, lactose and atropine}

During a study of the effects of various pharmacologic agents on the stomach, Tom was repeatedly given prostigmine, an agent which predictably induced abdominal cramps and diarrhea as well as hyperaemia, hypersecretion and hypermotility in the stomach. Figure 7 shows the typical effect of the prostigmine on the stomach. Each day, following the prostigmine, regardless of what substance was administered to Tom he displayed gastric hyperfunction, abdominal cramps and diarrhea. Figure 8 illustrates the apparent stimulating effect of the ingestion of $20 \mathrm{cc}$. of ordinary tap water and in Figure 9 one sees, following administration of two large red lactose capsules, hyperaemia, engorgement and hyperacidity in the stomach exceeding in intensity the effect of prostigmine and associated with abdominal cramps and diarrhea. Finally, an attempt was made to interrupt this unsalutary chain of events by the administration of hypodermic of $0.0006 \mathrm{Gm}$. of atropine sulfate. The results are shown in Figure 10. Again hyperaemia, hypersecretion and hypermotility occurred. For comparison the usual inhibiting effect of atropine on gastric function is also illustrated.

Comment. Such a reversal of the usual effect of atropine has been also observed in the colon by Grace and reported in detail elsewhere (12). The experimental subject was a 28 year old man with a large colonic fistula through which approximately 12 inches of cecum and ascending colon had evaginated and lay exposed on his abdominal wall. The administration of atropine was usually followed by pallor and dryness of the mucosa and interruption of contractile activity of the colon, but when the subject reacted to the experimental procedure with anger and hostility, as much as $0.012 \mathrm{Gm}$. of atropine administered intravenously was followed by hyperaemia, increased tone and hypermotility in the colon.

\section{DISCUSSION}

The experiences related above encountered in the course of testing the pharmacologic action of various agents on various organs of the body could probably be reproduced in almost any organ system.

The fact that "placebo effects" occur depends, of course, on the generalization established repeatedly by numerous workers that the mechanisms of the human body are capable of reacting not only to direct physical and chemical stimulation but also to symbolic stimuli, words and events which have somehow acquired special meaning for the individual.

The frequency with which "placebo effects" would be expected and their magnitude probably vary from person to person and from time to time. Although in Tom more than 100 experiments have been performed with pharmacologic agents, it is not possible to state with certainty how frequently significant modification of the pharmacologic effect occurred by reason of situational factors, but in retrospect one can detect minor evidences of such in well over $50 \%$ of observations. Tom is a comparatively healthy, active and productive human subject, whose detailed personality study is available elsewhere (1).

Not only the frequency but also the magnitude of "placebo effects" is impressive and deserves attention in pharmacologic experimentation in animals and man. It is at present customary to control drug experiments on various clinical syndromes with placebos especially when the data to be evaluated are chiefly subjective but, when objective recording of indicators of the agents' effects are available, placebo control is not generally practiced. The need for such controls is suggested by the fact that "placebo effects" include objective changes at the end organ which may exceed those attributable to potent pharmacologic action. Indeed, the pharmacologic action of an agent may be outweighed and its effect thus reversed.

\section{CONCLUSION}

"Placebo effects" which modify the pharmacologic action of drugs or endow inert agents with potency are not imaginary, but may be asso- 
ciated with measurable changes at the end organs. These effects are at times more potent than the pharmacologic action customarily attributed to the agent.

Thus the familiar difficulty of evaluating in patients new therapeutic agents stems not only from inadequately curbed enthusiasm of the investigator, but also from the actual physiologic effects of their "placebo" action.

\section{BIBLIOGRAPHY}

1. Wolf, S., and Wolff, H. G., Human Gastric Function: An Experimental Study of a Man and His Stomach. Oxford Univ. Press, New York, 1947, Ed. 2.

2. Sandweiss, D. J., Anti-ulcer (anthelone) products in the treatment of peptic ulcer. Gastroenterology, $1946,6,604$.

3. Greengard, H., Atkinson, A. J., Grossman, M. I., and Ivy, A. C., The effectiveness of parenterally administered "enterogastrone" in the prophylaxis of recurrences of experimental and clinical peptic ulcer, with summary of 58 cases. Gastroenterology, 1946, 7, 625.

4. Levin, E., Kirsner, J. B., and Palmer, W. L., Preliminary observations on histamine and insulin stimulated gastric secretion during the injection of an enterogastrone concentrate in man. Gastroenterology, 1948, 10, 274.
5. Ferayorni, R. R., Code, C. F., and Morlock, C. G., The effect of enterogastrone concentrates on gastric secretion in human beings. Gastroenterology, 1948, 11, 730.

6. Page, R. C., and Heffner, R. R., Oral treatment of chronic duodenal and jejunal ulcers with an extract of pregnant mare's urine. Gastroenterology, 1948, 11, 842.

7. Moersch, R. U., Rivers, A. B., and Morlock, C. G., Some results of the gastric secretory response of patients having duodenal ulcer noted during the administration of benadryl. Gastroenterology, 1946, 7, 91.

8. McElin, T. W., and Horton, B. T., Clinical observations on the use of benadryl : its effect on histamineinduced gastric acidity in man. Gastroenterology, 1946, 7, 100.

9. Holmes, T. H., Goodell, H., Wolf, S., and Wolff, H. G., The Nose: an experimental study of reactions within the nose in human subjects during varying life experiences. Charles C. Thomas, Springfield, Ill. In press.

10. Wolf, S., The relation of gastric function to nausea in man. J. Clin. Invest., 1943, 22, 877.

11. Wolff, H. G., and Goodell, H., The relation of attitude and suggestion to the perception of and reaction to pain. A. Research Nerv. \& Ment. Dis., 1943, 23, 434.

12. Grace, W. J., Wolf, S., and Wolff, H. G., The Human Colon. Paul Hoeber \& Co. In preparation. 